\title{
Novos tempos pedem novas narrativas na educação das artes visuais
}

\section{Resumo}

Esse texto reflete sobre o atual momento social e a urgencia de construção de novas narrativas para a educação e mais especificamente a educação das artes visuais. Para tanto, centra o pensamento nas mudanças nos conceitos de arte e infância. Considera que os estudos da cultura visual podem ser uma perspectiva nessa direção, por sua transdisciplinaridade e pelo deslocamento no papel das imagens como construtores de identidades e subjetividades. Aliada aos estudos da cultura visual leva nos a pensar numa relação dialógica na perspectiva bakhtiniana como nova narrativa na formação dos professores e professoras. 


\section{Abstract}

The text offers a reflection about the present social moment and the increasing need towards the construction of new narratives for the field of Education, more specifically, for the education of visual arts. To do so, the paper focuses on the changes regarding the concepts of art and childhood. The text highlights the fact that the studies about visual culture may present a horizon in that direction due to their transdisciplinary nature as well as to the displacement of he role of images as producers of identities and subjectivities. It is possible to think the studies of visual culture through a Bakhtinian dialogical view in order to build up new narratives in the education of the professors. 
Há um consenso de que vivemos uma mudança histórica para uma nova forma de capitalismo: pós-industrial, tardio, flexível. Essas mudanças que se perfilam desde a economia pelos meios de comunicação e as novas tecnologias, perpassando pelo pensamento neoliberal, afetam nossas vidas cotidianas e têm mudado de modo drástico as relações sociais, políticas, econômicas, culturais, artísticas e até nossas vidas.

Costa pontua as marcas dessas transformações na mudança histórica de uma nova forma de capitalismo como:

Marcado, entre outras coisas, pelo mundo disperso e efêmero das novas tecnologias, pelo consumo de toda a sorte de produtos da indústria cultural (inclusive imagens, identidades e modos de ser), por variadas e difusas políticas de identidade, por conformações de curto prazo e grande flexibilidade no trabalho, dificultando às pessoas, como diz Sennet (1998), a construção de uma narrativa coerente para suas vidas, vem nos inscrevendo em um mundo radicalmente diverso daquele em que vivíamos até, pelo menos, há uns 30 ou 40 anos. (COSTA, 2005 p.209).

Dentre as profundas mudanças, trataremos de algumas que dizem respeito a mudanças na educação e mais especificamente em artes visuais.

Nas últimas décadas, a noção de arte se expandiu. A centralidade da arte como espaço privilegiado da estética deu lugar à ascensão da cultura como espaço do estético, centralizado na cultura de massa, na publicidade, etc. O artista, como criador, inovador e com a missão de ser "salvador" através da estética, agora, desdobra-se no reconhecimento de seu parentesco com a arte, nos domínios do design, da moda, da decoração, do artesanato.

Nesse contexto, cabe-nos pensar que as narrativas modernas para a educação e o ensino das artes visuais perderam sua validade e o espaço de construçâo de novas narrativas tem urgência de ser pensado, experimentado, debatido, inventado.

Novas experiências e sensibilidades forjadas na vida social contemporânea afetam os sujeitos escolares desde a infância. Esses sujeitos chegam à escola com conhecimentos que desafiam narrativas tradicionais baseadas na transmissão dos conteúdos e na autoridade do professor ou professora. Desde sua entrada na escola, possuem conhecimentos e questionamentos sobre diversos temas 
da vida adulta, política e social, com versões das mídias sobre o ser e o sentir. Os sujeitos infantis chegam à escola já possuidores de uma bagagem de vivências e de prazer com narrativas visuais, sonoras e corporais da cultura popular, no seu cotidiano.

Para Traffi, as vinculações entre os estudos de cultura popular na perspectiva da cultura visual e os estudos críticos da infância dar-se-iam na liberação

\begin{abstract}
dos meninos e meninas dos limites que os adultos lhes impuseram, descrever a infância não somente como parte de uma ordem educativa que supostamente os ajuda a sobreviver, e sim analisá-la como parte de uma ordem discursiva que incorpora relações de saber-poder e formas de categorização historicamente construídas que conformam trajetos sociais e modelos de institucionalização e disciplinarização. Desta maneira, a despedagogização teria como finalidade entender o menino e a menina como produtor cultural e social, como construtor original de universos sociais compartilhados em comunidades infantis, de adultos e mista. (TRAFFI, 2005, p.42).
\end{abstract}

Nessa perspectiva, a autora ainda denuncia que "poucos estudos históricos têm abordado a reconstrução dos processos de consumo e os prazeres visuais da cultura popular, por parte dos mais pequenos." (TRAFFI, 2005, p.43).

Sendo assim, pensamos que o enfoque da cultura visual, como campo transdisciplinar que desafia os limites da história da arte e das obras artísticas e desloca a análise para o campo da cultura, é um campo de possibilidades para inventar novas narrativas para a educação e o ensino das artes visuais. Novas narrativas mais de acordo com o contexto contemporâneo, criando e desafiando interpretações que permitam às crianças e jovens de hoje se posicionarem criticamente como consumidores de imagens, construtores de identidades e subjetividades no contato cotidiano com o imaginário das corporações. "As organizações que criaram esse currículo cultural não são educacionais e sim comerciais, que operam não para o bem social mas para o ganho individual". (STEINBERG e KINCHELOE, 2004, p.15).

\title{
Cultura visual como perspectiva para a construçâo de novas narrativas para a educação
}

De acordo com Mirzoeff, (2003, p. 22) "A cultura visual não depende das imagens em si mesmas, mas da tendência moderna 
de plasmar em imagens ou visualizar a existência." Chamando atenção de que esse caráter visualizador do mundo e da vida não é um processo novo, o que o caracteriza como novo é "precisamente por centrar-se no visual como um lugar em que se criam e se discutem significados".

Uma vez que os lugares estruturados para a experiência visual - como ir ao cinema, ver televisão ou ir ao museu - deixam de ser os lugares de excelência do visual e se expandem para a vida cotidiana, desde a reprodução de uma obra em capas de livros ou em um anúncio, um filme em vídeo visto em casa, no ônibus, "a cultura visual deverá explorar as ambivalências, os interstícios e lugares de resistência na vida cotidiana pós-moderna, do ponto de vista do consumidor" (MIRZOEFF, 2003, p. 27).

O contexto contemporâneo, aliado a novos estudos, como os estudos de cultura visual em uma perspectiva pós-estruturalista, nos permite repensar os conhecimentos acumulados, as construções discursivas e criá-los sob novas perspectivas, novos olhares, novas dimensões. Nesse sentido, vivemos uma situação interessante e desafiadora, tanto para a pesquisa como para a práxis escolar e a formação de professores e professoras, uma vez que a abertura de perspectivas nos exige fugir de posições prescritivas.

Hernández (2007, p. 46) considera que essas mudanças fazem com que "estejamos em um período de transição: está acontecendo uma mudança no objeto de estudo e de aprendizagem que significa passar da "arte" à "cultura visual". Esta mudança é tão importante como foi, na década de 1980, a passagem da autoexpressão à orientaçao disciplinar."

Inventariando a trajetória do ensino das artes visuais no contexto brasileiro, podemos pensar que a mudança de paradigma do expressivismo para a metodologia triangular se deu com embates de poder, entre discursos que resistiam à mudança de uma perspectiva e outros que exaltavam as novas propostas, que implicavam por sua vez, em mudanças na relação do papel do professor e da professora, mudança no papel da disciplina no campo educacional e na formação de professores (as).

A mudança atual, baseada nos estudos de cultura visual exige novas relações e novas formulações. Os estudos da cultura visual unem visualidade, vida cotidiana e cultura, tal como expressado por Hall (apud MIRSOEFF, 2003 p.49): "a prática cultural se converte em um 
campo com o qual nos comprometemos e elaboramos uma política". Quer dizer que a cultura é o lugar onde se definem identidades e assim, essas mudam de acordo com os interesses dos indivíduos e das comunidades, na perspectiva das realidades plurais que coexistem. Como explica Martins (2007, p. 26) "a cultura visual discute e trata a imagem não apenas pelo seu valor estético mas, principalmente, buscando compreender o papel social da imagem na vida da cultura."

Interrogar a natureza do ver e do ser visto é interrogar o mundo que vivemos. Investigar os valores e as intenções que se operam na produção das imagens, o que essas dizem de nós, como constroem nossas subjetividades, exige de nossos estudos e de nossa práxis escolar uma posição política, uma vez que estamos tratando de visões e versões de mundo.

Desde essa perspectiva, a imagem não é neutra nem passível de representação. As imagens são interpretadas e valores culturais são disseminados. As imagens dialogam, dizem de nós, dos outros. Têm pontos de vista.

Para Gadamer (1984) "toda a compreensão é sempre interpretação" ou, em outras palavras, é a maneira humana que possuímos para conhecer o mundo, maneira que está determinada pela imersão em um contexto social que condiciona a compreensão da realidade. A radicalidade histórica/cultural/lingüística possibilita uma forma de compreender/ interpretar, ao mesmo tempo que exclui outras, permitindo formas diferenciadas de compreender/interpretar em contextos diferentes.

Desde esses pontos de vista, na educação das artes visuais baseada na cultura visual, a interpretação torna-se a trama no qual diferentes vozes e relações de poder se constituem, se mesclam, se afastam, se entrelaçam em diferentes temporalidades.

Martins (2006, p.21) nos diz que:

O conceito de interpretação dialógica institui e ambienta o princípio de heterogeneidade, núcleo central das reflexões pósestruturalistas entrelaçadas nas práticas e termos de exclusão. Tais reflexões concentram seu foco no 'conceito de autor', nas 'teorias sobre o sujeito' e nas 'diversas identidades' que nos interpelam desde as imagens e obras de arte. Possibilitam, também, deslocamentos perceptivos e interpretativos que propõem mudanças na noção/ 
concepção de imagem e de arte apoiados na compreensão de que a imagem não contém uma verdade própria a ser encontrada, descrita ou decifrada.

A interpretação dialógica deve permitir que crianças e jovens compreendam o momento cultural que vivem de forma crítica e reflexiva para se tornarem autores e protagonistas do seu momento histórico e, principalmente na dialogia, abrir-se ao "outro" e a "outra", num processo de desenvolvimento ético, compartilhado, de liberação coletiva e pessoal.

Zavala estudiosa de Bakthin, acentua que no rico universo teórico desse autor, suas reflexões são atravessadas pelas noções de compreensão, responsabilidade, comunicação e aponta que para esse pensador compreender " significa captar o múltiplo, sentir as vozes em sua historicidade, incorporar o ouvinte." ( ZAVALLA, 1991, p. 52)

Numa posição dialógica bakthiniana, poderiamos pensar na interpretação do mundo social, isto é do sujeito e dos outros/ as, da cultura, da comunidade através do contexto visualizado e das múltiplas posições visualizadoras dos sujeitos na cultura contemporânea? Nessa perspectiva, o princípio dialógico, desloca as posições individuais e hierárquicas, aonde o entrecruzamento de vozes se opõe ao discurso único, monológico da autoridade e do poder. Desde aí, uma mudança metodológica e epistemológica se impõe.

Os textos visuais são carregados de vozes, a nossa, a alheia, a da cultura, das corporações, do consumo, do passado, de gênero, de etnia, de classe, enfim, são discursos que dialogicamente nos atravessam, operam deslocamentos e nos constroem como sujeitos.

\section{A cultura visual e a formação de professores}

Os estudos da cultura visual não são estudos pedagógicos e a formação de professores não é tema desses estudos transdisciplinares. Considerando a perspectiva da cultura visual como base de novas narrativas para o ensino das artes visuais e para a educação escolar, podemos pensar que essa perspectiva exige mudanças na formação dos professores e professoras. E essas são mudanças profundas, pois pelas características dessa virada cultural, formas prescritivas seriam contraditórias e feririam na base novas narrativas desenvolvidas na interpretação dialógica. 
Repensar e reinventar a educação escolar, na pretensão de permitir aos sujeitos se construirem como sujeitos históricos e como cidadãos, participando da construção de identidades e subjetividades plurais é uma tarefa que exige reformulação na formação de professores.

Pois, como entender o menino e a menina como produtores culturais e sociais, como construtores originais de universos sociais, como propõe Traffi, se a formação desses profissionais não segue uma perspectiva que permita a construção desses sujeitos como produtores culturais?

Novas perspectivas que devem seguir as pistas da descontrução de suas formações, de um profundo exame e reflexividade de suas práticas, suas formações e trajetórias de vida e escolares.

Faz-se urgente a adoção de metodologias de investigação e práticas de formação que possam incorporar a voz do/a docente.

A noção de voz do docente é importante por que traz consigo o tom, a linguagem, a qualidade e os sentimentos que emolduram a forma de escrever e de falar de cada professor e professora. Num sentido político, aponta o direito a falar e ser representado. Pode dar conta tanto da voz individual como da coletiva, que é caracteristica do professorado e diferente da de outros grupos. (BUTT, RAYMOND, MC CUE E YAMAGISHI, apud GOODSON, 2004, p. 105)

\section{Concluindo....}

Se vivemos um tempo de transição, na arte e na educação, nos conceitos de infância e adolescente, que implica redimensionamento na formação de professores e professoras, na concepção do papel educativo da arte na educação escolar, em novas formas de ensinar e aprender, este tempo reflete modos filosóficos e epistemológicos de compreender e fazer ciência, de compreender e fazer arte e educação. Sob novas bases, principalmente as teorias "pós" que questionam e revisam as bases modernas, estamos hoje na perspectiva da arte em educação como um espaço de construção que exige que sejamos sujeitos, criativos e criadores de novas práxis. Pois, como diz Lortie, (1975 apud GOODSON, 2004, p. 27) "a educação é rica em prescrições e pobre em descrições” e se prescrições resolvessem as problemáticas educacionais, a modernidade não estaria no centro da crítica. 
Vivemos um tempo que instiga e desafia-nos a criar outras formas e modos de fazer educação, estabelecendo pontes com a vida cotidiana, com os artefatos visuais, sonoros, tácteis da indústria cultural, com as obras de arte contemporânea, com obras de arte de outros tempos, com o diálogo entre imagens de diferentes produções e, principalmente, ouvir a criança e o adolescente, sempre num processo contínuo de indagação.

A formação de professores e a pesquisa na área é, no meu entendimento, o grande desafio que vivemos nesse período de transição dentro da história da arte em educação em que estamos inseridos.

Como professores/as de arte na contemporaneidade que têm uma história, estamos sendo desafiados a ser inventivos, criativos e ousados para inventar novas práxis, novas posturas e novos modos de fazer pesquisa. Ser sujeito e autor de um momento da educação e arte é talvez, a lição mais importante que devemos tirar desse momento de transição. Como Hernández (2007) desafia-nos com suas propostas construídas como um patchwork de narrativas, convidando-nos a entrar nesse diálogo e não apenas reproduzi-lo.

Da aprendizagem da minha experiência vivida como professora de arte e construtora dessa história, quero voltar a acreditar que a práxis educativa em cultura visual pode contaminar, contribuir para repensar a educação e acreditar na possibilidade de inventar novas narrativas.

Novos tempos exigem novas narrativas educacionais. Se essas não mudarem, permanecerão as crises atuais, em que meninos e meninas logo perdem a vontade de freqüentar a escola e reagem com desinteresse ou com "problemas de disciplina."

Nas lutas de concorrência entre saber e poder pelos significados, as narrativas educacionais tradicionais estão perdendo terreno para as narrativas atraentes das corporações e do mercado na construção de identidades e subjetividades.

\section{Referências Bibliográficas}

BUJES, Maria Isabel E. Infância e Poder: breves sugestões para uma agenda de pesquisa. In: COSTA, Marisa Vorraber e Bujes, Maria Isabel. (orgs). Caminhos Investigativos III: riscos e possibilidades de pesquisar nas fronteiras . Rio de Janeiro: DP\&A, 2005 p.179-197. 
COELHO, R. Construcciones subjetivas y transformaciones sociales de jovenes y adultos brasileños: un estudio de historias de vida. 2006. 269 f. Tese (Doutorado em Ensino das Artes Visuais) Faculdade de Belas Artes, Universidade de Barcelona, Barcelona.

COSTA, Marisa Vorraber. Velhos temas, novos problemas: a arte de perguntar em tempos pós-modernos. In: COSTA, M. V; E Bujes, M.I. (orgs). Caminhos Investigativos III: riscos e possibilidades de pesquisar nas fronteiras . Rio de Janeiro: DP\&A, 2005. p. 199-213

GOODSON, Ivor. Historias de vida del profesorado. Barcelona: Octaedro, 2004. $313 \mathrm{p}$.

HERNÁNDEZ, Fernando. Consideraciones sobre el sujeto y la identidad en la educación escolar. Kikiriki: Cooperación Educativa, 51, 1998-1999 p. 21-26.

Catadores da cultura visual: transformando fragmentos em nova narrativa visual. Porto Alegre: Mediação, 2007. 127 p.

MARTINS, Raimundo. A cultura visual e a construção social da arte, da imagem e das práticas do ver. In: Oliveira, Marilda. (org.). Arte, educação e cultura. Santa Maria: Editora da UFSM, 2007. p. 19-40.

MIRZOEFF, Nicholas. Una introducción a la cultura visual. Tradução de Paula Garcia Segura. Barcelona: Paidós, 2003. 213 p.

STEINBERG, Shirley; KINCHELOE, Joe. Cultura Infantil: a construção corporativa da infância. Rio de Janeiro: Civilização Brasileira, 2004. 415 p.

JORNADES DE HISTÓRIA DEL EDUCACIÓ ARTÍSTICA. VI, 2006, Terrassa y Barcelona. Anais. Barcelona, UB, 2006. 229 p. TRAFFI, Laura. Reconstruir las historias de la educación artística y de la infancia desde una política crítica de las representaciones en el arte, la cultura y la cotidianeidad. In:, p. 35-6o.

ZAVALA, Iris. La posmodernidad y Mijail Bajtin: Una poética dialógica. Madrid: Espasa-Calpe, 1991. 276 p. 


\section{ROSEANE MARTINS COELHO}

É licenciada em Artes Plásticas, , mestre em Educaçao pela UFSC e doutora em Ensino e Aprendizagem das Artes Visuais pela Universidade de Barcelona. Bolsista CAPES para Doutorado Pleno no Exterior, 2002-2006. Foi professora do ensino fundamental no Magistério Público do Estado de Santa Catarina. Professora Adjunta do Centro de Educaçao da Universidade Federal de Santa Maria. Pesquisadora do GEPAEC.

E-mail: rocoelhozooo@yahoo.com 